\title{
GAMBARAN TRIANGULAR OF LOVE PADA PASUTRI PASCA MELAHIRKAN
}

\author{
Evelyn Cindy ${ }^{1}$, Linda Wati ${ }^{2}$, Erik Wijaya ${ }^{3}$. \\ ${ }^{1}$ Jurusan psikologi, Universitas Tarumanagara \\ Email : Epinepin26@gmail.com \\ ${ }^{2}$ Jurusan psikologi, Universitas Tarumanagara \\ Email : Lindaw@fpsi.untar.ac.id \\ ${ }^{3}$ Jurusan psikologi, Universitas Tarumanagara \\ Email : Erikw@fpsi.untar.ac.id
}

\begin{abstract}
ABSTRAK
Perubahan yang terjadi pada ibu pasca melahirkan dapat membawa dampak terutama dalam hubungan terhadap pasangan. Perubahan tersebut antara lain perubahan fisik, perubahan dalam melakukan hubungan seksual, perubahan emosi dan mengurus anak. Fenomena perubahan yang terjadi pada ibu setelah pasca melahirkan dapat berdampak pada hubungan terhadap pasangan terutama dalam hal intimacy, passion, dan commitment. Robert Sternberg mengemukakan ketiga unsur cinta yaitu intimacy, passion, dan commitment haruslah seimbang agar menciptakan hubungan yang baik dan tahan lama (Papalia et al., 2009). Penelitian ini adalah penelitian kuantitatif yang bertujuan untuk mengetahui gambaran triangular of love pada pasutri pasca melahirkan. Pengambilan data dalam penelitian ini dilakukan pada tanggal 12 April 2015 di Jakarta dengan melibatkan 392 pasang suami istri sebagai partisipan. Kriteria subyek yang digunakan dalam penelitian ini adalah pasangan suami istri yang berusia 21-40 tahun dan memiliki anak yang berusia enam minggu hingga empat tahun. Alat ukur yang digunakan dalam penelitian ini adalah Sternberg Triangular Love Scale. Hasil penelitian menunjukkan dari ketiga dimensi yaitu intimacy, passion, dan commitment dimensi passion adalah dimensi yang paling rendah diantara dimensi intimacy dan commitment pada pasangan pasca melahirkan. Hasil juga menunjukan jika dilihat dari triangular love suami dari 392 subyek yaitu; a) 1 subyek cenderung rendah pada dimensi intimacy suami, b) 10 subyek cenderung rendah pada dimensi passion suami, dan c) cenderung tinggi 392 subyek pada dimensi commitment suami. Sedangkan, pada triangular love istri dari 392 subyek didapatkan hasil berupa; a) 6 orang cenderung rendah pada dimensi intimacy istri, b) 5 orang cenderung rendah pada dimensi passion istri, dan c) cenderung tinggi 392 subyek pada dimensi commitment istri.
\end{abstract}

Kata kunci: triangular love, intimacy, passion, commitment

\section{PENDAHULUAN}

\section{Latar Belakang}

Setelah melalui proses melahirkan, perempuan berada pada tahap pasca melahirkan, atau yang biasa disebut dengan masa pascapartum. Periode ini dimulai selama enam minggu yaitu sejak bayi lahir sampai organ-organ reproduksi kembali ke keadaan normal sebelum hamil. Periode ini kadang-kadang juga disebut puerperium atau trimester keempat dari tahapan kehamilan (Bobak \& Irene, 2005). Masa nifas atau puerperium dimulai sejak 1 jam setelah keluarnya plasenta (ariari) sampai dengan 6 minggu (42 hari) setelahnya (Prawirohardjo, 2008). Pasangan suami istri yang memiliki bayi akan mengalami kebahagiaan di satu sisi dan berbagai persoalan di sisi lainnya. Persoalan-persoalan tersebut terjadi karena perubahan yang terdapat setelah seorang perempuan melalui tahapan melahirkan. Perubahan tersebut antara lain fisik, emosi, hubungan seksual dan mengurus anak. Perubahan fisik dapat dilihat dari kenaikan berat badan. Perubahan berat badan biasanya mulai nampak mulai dari proses kehamilan dan sering kali terbawa hingga setelah melahirkan. Bagi wanita yang sangat memperhatikan bentuk tubuh (BMI: Body Mass Index $<19,8$ ), peningkatan berat badan merupakan masalah besar. Wanita yang berat badannya meningkat pada masa kehamilan akan memiliki kemungkinan lebih besar tetap gemuk setelah melahirkan (Bobak \& Irene, 2005). 
Sebuah survey dari dailymail dilakukan pada 793 ibu yang baru melahirkan menunjukkan bahwa mayoritas mereka tidak puas pada bentuk tubuh setelah melahirkan. Satu dari lima wanita mengaku merasa tertekan karena suami mereka tidak suka dengan bentuk tubuh setelah melahirkan. Para suami ingin agar istrinya segera langsing (Yel, 2013). Perubahan fisik lainnya juga termasuk perubahan rambut rontok dalam jumlah banyak, kemudian kulit wajah berjerawat akibat kadar hormon tidak stabil. Selain itu hidung, telinga dan mulut juga mengalami perubahan karena produksi hormon (Danuatmadja, 2003).

Perubahan fisik selanjutnya adalah leher, leher menjadi agak membengkak karena kelenjar tiroid membengkak selama masa kehamilan. Payudara juga mengalami perubahan baik pada ibu yang memberikan asi maupun tidak memberikan asi. Kemudian pada leher rahim, setelah melewati proses melahirkan leher rahim akan turun hingga ke vagina, serta terdapat perubahan pada lendir leher rahim. Pada kaki dan tangan juga terjadi pembengkakan karena perubahan akibat hormon progesterone dan relaksin. Terdapat juga perubahan pada kandung kemih yang mengakibatkan rasa tertekan dan tidak nyaman saat buang air kecil. Perubahan terakhir yaitu pada alat kelamin yang warnanya terlihat lebih gelap dan terjadi peregangan pada otot-otot dinding vagina (Danuatmaja, 2003).

Perubahan yang lainnya adalah perubahan dalam melakukan hubungan seksual. Sebuah studi dilakukan di Rumah Dustira Cimahi pada bulan April 2011. Pada studi tersebut subyek yang digunakan adalah sembilan ibu bersalin normal dan satu ibu bersalin melalui operasi caesarea. Dari hasil wawancara tiga ibu mengatakan mulai berhubungan seksual kira-kira tiga bulan setelah melahirkan. Sementara itu, tujuh diantaranya mengatakan belum memikirkan tentang kapan akan mulai berhubungan seksual lagi (Suryati \& Elliya, 2011). Padahal hubungan seksual merupakan salah satu faktor yang penting dalam sebuah pernikahan yang termasuk dalam aspek kasih sayang (Rice, 1999).

Selain itu, terdapat juga perubahan emosi yang dapat menimbulkan gangguan yang biasa disebut dengan baby blues. Baby blues adalah istilah yang diperuntukkan bagi perasaan sedih tanpa dasar yang terjadi setelah seseorang wanita melahirkan bayinya biasanya terjadi selama dua minggu setelah melahirkan (Murtiningsih, 2012). Jika baby blues berlangsung selama lebih dari dua minggu, maka akan menjadi depresi postpartum. Depresi postpartum dapat ditimbulkan dari beberapa faktor, dikutip dari penelitian faktor-faktor yang berhubungan dengan depresi postpartum di RSIA Pertiwi Makassar tahun 2012 (Ibrahim, Rahma \& Ikhsan, 2012). Dilihat dari pekerjaan ibu subyek yang tidak bekerja sebanyak enam orang dan yang bekerja sebanyak sembilan orang menunjukkan hasil bahwa depresi postpartum sebagian besar terdapat pada subyek yang tidak bekerja.

Kemudian faktor lainnya yang berhubungan dengan depresi pasca melahirkan adalah tingkat pendidikan. Dalam penelitian Ibrahim dan rekan-rekan (2012), dari tujuh subyek yang berpendidikan tinggi dan delapan subyek yang berpendidikan rendah menunjukkan bahwa subyek yang paling banyak mengalami depresi adalah tingkat subyek yang berpendidikan tinggi. Hal ini disebabkan karena perempuan yang berpendidikan tinggi menghadapi tekanan sosial dan konflik peran antara tuntutan dorongan untuk bekerja dengan peran sebagai ibu rumah tangga. Status sosial ekonomi juga dapat menjadi faktor penyebab depresi, hasil menunjukkan dari sebelas subyek yang memiliki status sosial ekonomi kurang dan empat subyek yang memiliki status sosial ekonomi cukup, depresi sebagian besar terdapat pada subyek yang memiliki status sosial ekonomi kurang. 
Depresi yang dialami oleh ibu pasca melahirkan sebenarnya dapat diminimalkan melalui dukungan dari keluarga dan pasangan. Ibrahim dan rekan-rekan (2012) menemukan dalam penelitiannya bahwa sebanyak delapan subyek yang kurang mendapat dukungan sosial dari suami, tujuh subyek yang cukup mendapat dukungan dari suami, serta delapan subyek yang kurang mendapat dukungan sosial dari keluarga, dan tujuh subyek yang cukup mendapat dukungan dari keluarga menunjukkan bahwa depresi postpartum sebagian besar terdapat pada subyek yang kurang mendapat dukungan sosial dari suami dan keluarga.

Perubahan yang terjadi pada ibu pasca melahirkan dapat membawa dampak terutama dalam hubungan terhadap pasangan. Sebuah survei dilakukan oleh The Wall Street Journal pada 2900 subyek yang baru memiliki bayi pertama mereka menunjukkan hasil paling tinggi sebanyak $28,5 \%$ pada subyek yang mengatakan memiliki bayi merusak kebahagiaan pernikahan mereka (Petersen, 2011). Kemudian, pada sebuah jurnal dilakukan penelitian untuk melihat kepuasan pernikahan setelah menjadi orangtua. Data diambil dua kali, masing-masing sebelum pasangan memiliki anak dan setelah memiliki anak pertama mereka pada subyek yang berjumlah 156 pasang, didapatkan hasil bahwa menjadi orangtua mempercepat penurunan kepuasan pernikahan mereka (Lawrence, Cobb, Rothman \& Bradbury, 2008).

Meijer dan Wittenboer (dikutip oleh Papalia, Wenkos-Olds \& Feldman, 2009) mengatakan bahwa hal yang terlihat mudah seperti saat bayi menangis yang membangunkan orangtua di malam hari dapat menurunkan kepuasan pernikahan selama tahun pertama menjadi orangtua. Terdapat beberapa sumber stress setelah kelahiran bayi, antara lain kesehatan bayi, saat bayi menangis, interaksi dengan pasangan (termasuk hubungan seksual), hubungan dengan keluarga, kecemasan dan depresi (Strong, DeVault, Cohen 2011).

Perubahan dalam kualitas pernikahan dan konfik dalam pernikahan dijelaskan dalam studi longitudinal dari pasangan kulit putih dan Afrika Amerika yang mengalami transisi menjadi orangtua dalam 2 tahun pertama pernikahannya. Pasangan kulit putih dan Afrika Amerika yang menjadi orangtua dilaporkan rendah dalam kebahagiaan pernikahan dan lebih banyak mengalami konflik dalam masa transisi menjadi orangtua dibandingkan dengan sebelumnya (Crohan dikutip dalam Rice 1999). Perubahan dalam kepuasan pernikahan dan peningkatan konfik dalam pernikahahan serta penurunan interaksi dengan pasangan adalah hal yang umum terjadi selama transisi menjadi orangtua (Strong 2011).

Fenomena di atas menunjukkan bahwa perubahan yang terjadi pada ibu setelah pasca melahirkan dapat berdampak pada hubungan terhadap pasangan terutama dalam hal intimacy, passion, dan commitment. Faktor-faktor yang berpengaruh terhadap kepuasan pernikahan antara lain adalah terdapatnya intimacy, passion dan commitment dalam sebuah hubungan. Pada sebuah jurnal yang mengambil subyek sebanyak 400 pasangan yang telah menikah, menunjukkan bahwa intimacy, passion, dan commitment signifikan terhadap kepuasan kehidupan pernikahan mereka (Carandang \& Guda, 2015).

Temuan (Retnaningtyas, 2007), pada jurnal yang berjudul komponen cinta pada individu yang telah menikah menurut triangular theory of love, mengambil subyek sebanyak enam orang yang telah menjalani usia pernikahan selama tujuh sampai sembilan tahun dan sudah memiliki anak. Hasil menunjukkan bahwa keenam subyek masih memiliki komponen cinta Sternberg, namun komponen cinta dari masing-masing subyek mempunyai kekuatan yang berbeda-beda. Jadi pada masing-masing subyek ada komponen cinta yang paling menonjol. Hal ini sejalan dengan yang 
dikemukakan oleh Robert Sternberg yaitu, ketiga unsur cinta intimacy, passion, dan commitment haruslah seimbang agar menciptakan hubungan yang baik dan tahan lama (Papalia et al., 2009).

Sternberg (dikutip oleh Papalia et al., 2009), mengungkapkan mengenai teori triangular of love, di mana di dalamnya terdapat unsur intimacy, passion, dan commitment. Intimacy adalah elemen yang emosional, melibatkan pengungkapan diri, yang mengarah ke hubungan, kehangatan, dan kepercayaan. Passion, adalah elemen motivasi, didasarkan pada dorongan yang diartikan dalam psikologi sebagai gairah yang menjadi hasrat seksual. Commitment, adalah elemen kognitif, merupakan keputusan untuk mencintai dan tetap bersama orang yang dicintainya (Papalia et al., 2009). Ketiga unsur tersebut harus seimbang guna mencapai hubungan yang baik dan tahan lama seperti yang telah diungkapkan di atas. Dari paparan diatas, dapat dilihat bahwa perubahanperubahan yang terjadi pascamelahirkan dapat berdampak bagi hubungan suami istri khususnya pada unsure intimacy, passion, dan commitement. Oleh karena, itu penelitian ini bertujuan untuk melihat gambaran triangular of love of pada pasutri pasca melahirkan dilihat dari berbagai aspek.

\section{Rumusan Masalah}

Melihat gambaran triangular of love pada pasutri pasca melahirkan.

\section{METODE PENELITIAN}

Makalah dapat ditulis baik dalam bahasa Indonesia maupun Inggris. Tulisan dalam pokok uraian menggunakan jenis huruf Times New Roman ukuran 12 pt, justified, 1 spasi, sebagaimana pada dokumen ini. Penulis diperbolehkan menggunakan huruf jenis lain untuk keperluan khusus misalnya untuk membedakan source code suatu program komputer.

Judul dari suatu section (heading dari section) ditulis dengan Times New Roman Capital 12 pt, bold. Penomoran dimulai dengan angka 1, 2, 3, dst. Format paragraf justified, dan dalam satu halaman diusahakan rata atas dan bawah, sehingga sisa spasi dapat diatur oleh penulis. Penggantian alinea diberi jarak 1 spasi.

\section{Sub bagian (Sub section)}

Judul dari subsection ditulis dalam Times New Roman 12 pt, bold dan ditulis dengan model sentence case (huruf besar hanya pada awal). Judul Sub bagian ditulis tanpa nomor bab.

\section{HASIL DAN PEMBAHASAN}

Pada gambaran umum triangular of love suami setelah pasca melahirkan menggunakan skala 14, sehingga memiliki mean hipotetik alat ukur yaitu 2,5 sedangkan mean empirik triangular love pasca melahirkan adalah untuk masing-masing dimensi intimacy 3.4527, dimensi passion 3,1214, dan dimensi commitment 3,5692. Dapat dilihat bahwa skor empirik setiap dimensi lebih besar dari skor hipotetik, sehingga dapat dikatakan bahwa triangular of love tinggi atau cenderung tinggi. Dari antara ketiga dimensi, dimensi passion adalah dimensi yang memiliki skor empirik yang paling kecil jika dibandingkan dengan dimensi commitment dan dimensi intimacy. Hasil selengkapnya dapat dilihat pada tabel 1. 
Tabel 1. Gambaran Variabel Triangular of Love Suami

\begin{tabular}{cccccc}
\hline & $\mathrm{N}$ & Minimum & Maximum & Mean & Std. Deviation \\
\hline Intimacy Suami & 392 & 2.20 & 4.00 & 3.4527 & .34818 \\
Passion Suami & 392 & 2.20 & 4.00 & 3.1214 & .34913 \\
Commitment Suami & 392 & 2.80 & 4.00 & 3.5692 & .36787 \\
\hline
\end{tabular}

Pada gambaran umum triangular of love istri setelah pasca melahirkan menggunakan skala 1-4, sehingga memiliki mean hipotetik alat ukur yaitu 2,5 sedangkan mean empirik triangular love pasca melahirkan pada dimensi intimacy 3,3974 dimensi passion 3,1155 dan dimensi commitment 3,5639. Skor empirik masing-masing dimensi lebih besar dari skor hipotetik, sehingga dapat dikatakan bahwa triangular love tinggi atau cenderung tinggi. Dari ketiga dimensi, dapat dilihat bahwa dimensi passion memiliki nilai paling rendah jika dibandingkan dengan dimensi commitment dan dimensi intimacy. Hasil selengkapnya dapat dilihat pada tabel 2 .

Tabel 2. Gambaran Variabel Triangular of Love Istri

\begin{tabular}{cccccc}
\hline & $\mathrm{N}$ & Minimum & Maximum & Mean & Std. Deviation \\
\hline Commitment Istri & 392 & 2.87 & 4.00 & 3.5639 & .33156 \\
Passion Istri & 392 & 1.87 & 4.00 & 3.1155 & .36416 \\
Intimacy Istri & 392 & 2.33 & 4.00 & 3.3974 & .39139 \\
\hline
\end{tabular}

Pada uji beda terhadap triangular of love istri dengan rentang waktu melahirkan, terdapat beda signifikan yang didasarkan pada nilai $\mathrm{p}<0,05$. Hasil menunjukkan subyek yang memiliki intimacy paling tinggi adalah subyek yang melahirkan tahun 2015. Subyek yang memiliki passion paling tinggi adalah subyek yang melahirkan pada tahun 2011. Subyek yang memiliki commitment paling tinggi adalah subyek yang melahirkan pada tahun 2013. Sedangkan, subyek yang memiliki intimacy paling rendah adalah subyek yang melahirkan pada tahun 2013. Subyek yang memiliki passion paling rendah adalah subyek yang melahirkan pada tahun 2015 dan subyek yang memiliki commitment paling rendah adalah subyek yang melahirkan pada tahun 2015. Hasil selengkapnya dapat dilihat pada tabel 3. 
Tabel 3. Uji Beda Triangular of Love Istri dengan Rentang Waktu Melahirkan

\begin{tabular}{|c|c|c|c|c|}
\hline Dimensi & Waktu Melahirkan & Mean & $\bar{F}$ & $\bar{P}$ \\
\hline \multirow{5}{*}{ Intimacy } & 2011 & 3.6250 & \multirow{5}{*}{17.007} & \multirow{5}{*}{.000} \\
\hline & 2012 & 3.4485 & & \\
\hline & 2013 & 3.3236 & & \\
\hline & 2014 & 3.5861 & & \\
\hline & 2015 & 3.7641 & & \\
\hline \multirow{5}{*}{ Passion } & 2011 & 3.6536 & \multirow{5}{*}{4.561} & \multirow{5}{*}{.001} \\
\hline & 2012 & 3.3760 & & \\
\hline & 2013 & 3.3697 & & \\
\hline & 2014 & 3.3974 & & \\
\hline & 2015 & 3.1879 & & \\
\hline \multirow{5}{*}{ Commitment } & 2011 & 3.5067 & \multirow{5}{*}{9.035} & \multirow{5}{*}{.000} \\
\hline & 2012 & 3.5051 & & \\
\hline & 2013 & 3.7014 & & \\
\hline & 2014 & 3.6613 & & \\
\hline & 2015 & 3.4162 & & \\
\hline
\end{tabular}

Berdasarkan uji beda triangular of love istri dengan usia, terdapat beda signifikan yang didasarkan pada nilai $\mathrm{p}<0,05$. Hasil menunjukkan subyek yang memiliki intimacy paling tinggi adalah subyek yang berusia 22 tahun. Subyek yang memiliki passion paling tinggi adalah subyek yang berusia 22 tahun. Subyek yang memiliki commitment paling tinggi adalah subyek yang berusia 22 tahun. Sedangkan, subyek yang memiliki intimacy paling rendah adalah subyek yang berusia 33 tahun. Subyek yang memiliki passion paling rendah adalah subyek yang berusia 33 tahun dan subyek yang memiliki commitment paling rendah adalah subyek yang berusia 23 tahun.

Berdasarkan uji beda triangular of love suami dengan status sosial ekonomi, terdapat beda signifikan pada dimensi intimacy dan commitment yang didasarkan pada nilai $\mathrm{p}<0,05$. Hasil menunjukkan subyek yang memiliki intimacy paling tinggi adalah subyek dengan pendapatan > Rp 10.000.000. Subyek yang memiliki passion paling tinggi adalah subyek dengan pendapatan > $\mathrm{Rp}$ 10.000.000. Subyek yang memiliki commitment paling tinggi adalah subyek dengan pendapatan > Rp 10.000.000. Sedangkan, subyek yang memiliki intimacy paling rendah adalah subyek dengan pendapatan Rp 1.000.000 - Rp 5.000.000. Subyek yang memiliki passion paling 
rendah adalah subyek dengan pendapatan Rp 1.000 .000 - Rp 5.000 .000 dan subyek yang memiliki commitment paling rendah adalah subyek dengan pendapatan $\mathrm{Rp} 5.000 .000$ - Rp 10.000.000. Hasil selengkapnya dapat dilihat pada tabel 4.

Tabel 4. Uji Beda Triangular of Love Suami dengan Status Sosial Ekonomi

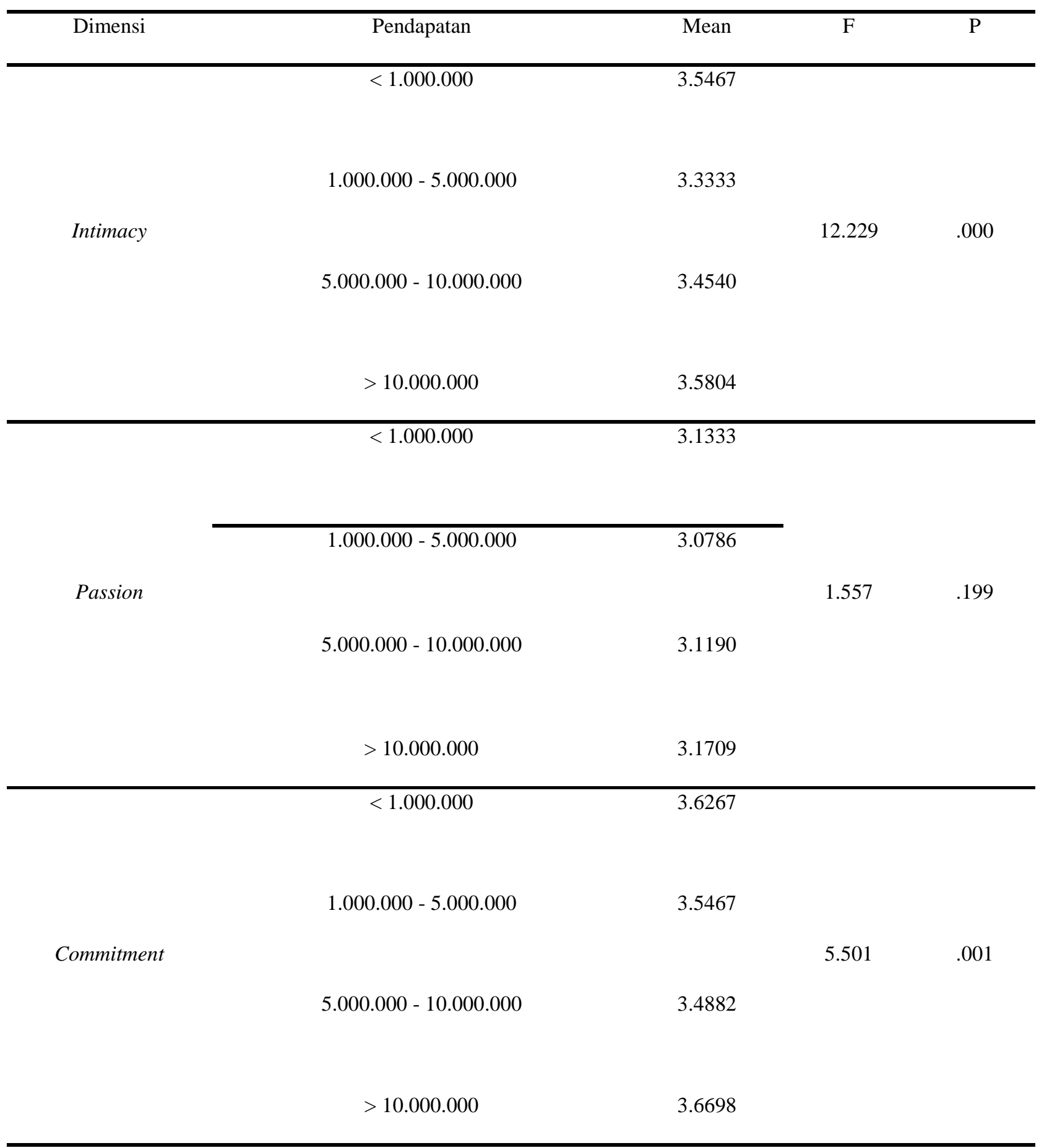


Berdasarkan uji beda triangular of love suami dengan pendidikan, terdapat beda signifikan pada dimensi intimacy, passion dan commitment yang didasarkan pada nilai $p<0,05$. Hasil menunjukkan subyek yang memiliki intimacy paling tinggi adalah subyek yang memiliki pendidikan S2. Subyek yang memiliki passion paling tinggi adalah subyek yang memiliki pendidikan S2. Subyek yang memiliki commitment paling tinggi adalah subyek yang memiliki pendidikan S2. Sedangkan, subyek yang memiliki intimacy paling rendah adalah subyek yang memiliki pendidikan SMA. Subyek yang memiliki passion paling rendah adalah subyek yang memiliki pendidikan lain-lain dan subyek yang memiliki commitment paling rendah adalah subyek yang memiliki pendidikan lain-lain. Hasil selengkapnya dapat dilihat pada tabel 5.

Tabel 5. Uji Beda Triangular of Love Suami dengan Pendidikan

\begin{tabular}{|c|c|c|c|c|}
\hline Dimensi & Pendidikan & Mean & $\mathrm{F}$ & $\mathrm{P}$ \\
\hline \multirow{6}{*}{ Intimacy } & SD & 3.6250 & \multirow{6}{*}{17.221} & \multirow{6}{*}{.000} \\
\hline & SMP & 3.4485 & & \\
\hline & SMA & 3.3236 & & \\
\hline & S1 & 35861 & & \\
\hline & S2 & 3.7641 & & \\
\hline & lain lain & 3.3524 & & \\
\hline \multirow{6}{*}{ Passion } & SD & 3.1167 & \multirow{6}{*}{20.489} & \multirow{6}{*}{.000} \\
\hline & SMP & 2.9818 & & \\
\hline & SMA & 2.9929 & & \\
\hline & S1 & 3.2871 & & \\
\hline & S2 & 3.4154 & & \\
\hline & lain lain & 2.8667 & & \\
\hline \multirow{7}{*}{ Commitment } & SD & 3.7417 & \multirow{7}{*}{15.248} & \multirow{7}{*}{.000} \\
\hline & SMP & 3.4788 & & \\
\hline & SMA & 3.4495 & & \\
\hline & & 260075 & & \\
\hline & $\mathrm{SI}$ & 3.6925 & & \\
\hline & S2 & 3.9179 & & \\
\hline & lain lain & 3.3810 & & \\
\hline
\end{tabular}


Berdasarkan uji beda triangular of love istri dengan pendidikan, terdapat beda signifikan pada dimensi intimacy yang didasarkan pada nilai $\mathrm{p}<0,05$. Hasil menunjukkan subyek yang memiliki intimacy paling tinggi adalah subyek yang memiliki pendidikan SD. Subyek yang memiliki passion paling tinggi adalah subyek yang memiliki pendidikan SD. Subyek yang memiliki commitment paling tinggi adalah subyek yang memiliki pendidikan SD. Sedangkan, subyek yang memiliki intimacy paling rendah adalah subyek yang memiliki pendidikan SMP. Subyek yang memiliki passion paling rendah adalah subyek yang memiliki pendidikan S2 dan subyek yang memiliki commitment paling rendah adalah subyek yang memiliki pendidikan S2. Hasil selengkapnya dapat dilihat pada tabel 6.

Tabel 6. Uji Beda Triangular of Love Istri dengan Pendidikan

\begin{tabular}{|c|c|c|c|c|}
\hline$\overline{\text { Dimensi }}$ & Pendidikan & Mean & $\bar{F}$ & $\bar{P}$ \\
\hline \multirow{7}{*}{ Intimacy } & SD & 3.7000 & \multirow{7}{*}{8.173} & \multirow{7}{*}{.000} \\
\hline & SMP & 3.2417 & & \\
\hline & SMA & 3.2807 & & \\
\hline & & & & \\
\hline & SI & 3.5163 & & \\
\hline & S2 & 3.4333 & & \\
\hline & lain lain & 3.2556 & & \\
\hline \multirow{6}{*}{ Passion } & SD & 3.4000 & \multirow{6}{*}{1.112} & \multirow{6}{*}{.353} \\
\hline & SMP & 3.1417 & & \\
\hline & SMA & 3.0742 & & \\
\hline & $\overline{S 1}$ & 3,1483 & & \\
\hline & $\mathrm{S} 2$ & 2.9667 & & \\
\hline & lain lain & 3.1556 & & \\
\hline \multirow{7}{*}{ Commitment } & $\overline{S D}$ & 3.9333 & \multirow{7}{*}{1.780} & \multirow{7}{*}{.116} \\
\hline & SMP & 3.3417 & & \\
\hline & SMA & 3.5504 & & \\
\hline & & & & \\
\hline & S1 & 3.5882 & & \\
\hline & $\mathrm{S} 2$ & 3.3333 & & \\
\hline & lain lain & 3.5000 & & \\
\hline
\end{tabular}


Berdasarkan uji beda triangular of love suami dengan pekerjaan, terdapat beda signifikan pada dimensi passion dan commitment yang didasarkan pada nilai $\mathrm{p}<0,05$. Hasil menunjukkan subyek yang memiliki intimacy paling tinggi adalah subyek yang bekerja. Subyek yang memiliki passion paling tinggi adalah subyek yang bekerja. Subyek yang memiliki commitment paling tinggi adalah subyek yang bekerja. Kemudian, pada uji beda triangular of love istri dengan pekerjaan menunjukkan subyek yang memiliki intimacy paling tinggi adalah subyek yang bekerja. Subyek yang memiliki passion paling tinggi adalah subyek yang bekerja. Subyek yang memiliki commitment paling tinggi adalah subyek yang tidak bekerja. Hasil selengkapnya dapat dilihat pada tabel 7 dan 8 .

Tabel 7. Uji Beda Triangular of Love Suami dengan Pekerjaan

\begin{tabular}{ccc}
\hline Dimensi & Pekerjaan & Mean \\
\hline Intimacy & Bekerja & 3.4539 \\
& Tidak Bekerja & 3.0000 \\
\hline Passion & Bekerja & 3.1217 \\
& Tidak Bekerja & 3.0000 \\
\hline Commitment & Bekerja & 3.5707 \\
& Tidak Bekerja & 3.0000 \\
\hline
\end{tabular}

Tabel 8. Uji Beda Triangular of Love Istri dengan Pekerjaan

\begin{tabular}{ccccc}
\hline Dimensi & Pekerjaan & Mean & F & P \\
\hline \multirow{2}{*}{ Intimacy } & Bekerja & 3.3986 & .011 & .916 \\
& Tidak Bekerja & 3.3963 & & .040 \\
Passion & Bekerja & 3.1470 & 4.233 & \\
& Tidak Bekerja & 3.0843 & & .000 \\
\hline \multirow{2}{*}{ Commitment } & Bekerja & 3.5562 & 13.432 & \\
& Tidak Bekerja & 3.5716 & & \\
\hline
\end{tabular}

Berdasarkan uji beda triangular of love suami dengan jumlah anak, terdapat beda signifikan pada dimensi commitment yang didasarkan pada nilai $\mathrm{p}<0,05$. Hasil menunjukkan subyek yang 
memiliki intimacy paling tinggi adalah subyek yang memiliki tiga anak. Subyek yang memiliki passion paling tinggi adalah subyek yang memiliki satu anak. Subyek yang memiliki commitment paling tinggi adalah subyek yang memiliki tiga anak. Sedangkan, subyek yang memiliki intimacy paling rendah adalah subyek yang memiliki dua anak. Subyek yang memiliki passion paling rendah adalah subyek yang memiliki tiga anak dan subyek yang memiliki commitment paling rendah adalah subyek yang memiliki dua anak. Hasil selengkapnya dapat dilihat pada tabel 9.

Tabel 9. Uji Beda Triangular of Love Suami dengan Jumlah Anak

\begin{tabular}{ccccc}
\hline Dimensi & Jumlah Anak & Mean & F & P \\
\hline \multirow{2}{*}{ Intimacy } & 1 & 3.4667 & & \\
\cline { 2 - 3 } & 2 & 3.4252 & 0.928 & 0,396 \\
& 3 & 3.4908 & & \\
Passion & 1 & 3.1520 & & 0.240 \\
& 2 & 3.0990 & 1.432 & \\
\hline \multirow{2}{*}{ Commitment } & 3 & 3.0766 & & 0.033 \\
& 1 & 3.6029 & & \\
\hline & 2 & 3.5115 & 3.443 & \\
\hline
\end{tabular}

Berdasarkan uji beda triangular of love istri dengan jumlah anak, terdapat beda signifikan yang didasarkan pada nilai $\mathrm{p}<0,05$. Hasil menunjukkan subyek yang memiliki intimacy paling tinggi adalah subyek yang memiliki dua anak. Subyek yang memiliki passion paling tinggi adalah subyek yang memiliki dua anak. Subyek yang memiliki commitment paling tinggi adalah subyek yang memiliki dua anak. Sedangkan, subyek yang memiliki intimacy paling rendah adalah subyek yang memiliki satu anak. Subyek yang memiliki passion paling rendah adalah subyek yang memiliki satu anak dan subyek yang memiliki commitment paling rendah adalah subyek yang memiliki tiga anak. Hasil selengkapnya dapat dilihat pada tabel 10. 
Tabel 10. Uji Beda Triangular of Love Istri dengan Jumlah Anak

\begin{tabular}{|c|c|c|c|c|}
\hline Dimensi & Jumlah Anak & Mean & $\mathrm{F}$ & $\mathrm{P}$ \\
\hline \multirow{3}{*}{ Intimacy } & 1 & 3.3523 & \multirow{3}{*}{2.375} & \multirow{3}{*}{0,094} \\
\hline & 2 & 3.4398 & & \\
\hline & 3 & 3.4326 & & \\
\hline \multirow{4}{*}{ Passion } & 1 & 3.0746 & \multirow{3}{*}{2.410} & \multirow{3}{*}{0.091} \\
\hline & 2 & 3.1602 & & \\
\hline & 3 & 3.1262 & & \\
\hline & 1 & 3.5373 & \multirow{3}{*}{7.352} & \multirow{3}{*}{0.001} \\
\hline \multirow[t]{2}{*}{ Commitment } & 2 & 3.6314 & & \\
\hline & 3 & 3.4411 & & \\
\hline
\end{tabular}

Berdasarkan paparan di atas, hasil triangular love tinggi atau cenderung tinggi, hal ini dapat disebabkan karena butir yang ada dalam alat ukur penelitian ini keseluruhannya merupakan butir positif. Hal ini membuat subyek memiliki kecenderungan untuk menjawab setuju. Sehingga kurang dapat menggali jawaban dari subyek. Selain itu, dari hasil yang di dapat juga menunjukkan bahwa dimensi passion lebih rendah dari pada dimensi intimacy dan commitment setelah pasca melahirkan. Hasil ini disebabkan karena kondisi ibu pasca melahirkan yang belum dapat berhubungan seksual hingga satu bulan setelah pasca melahirkan, atau bahkan untuk kasus khusus yang saat kelahiran memiliki masalah, hubungan seksual dapat tertunda lebih lama lagi.

Kondisi ini juga telah dikatakan oleh subyek yang telah diwawancara oleh peneliti. Dua orang subyek yang masing-masing melahirkan secara caesar dan normal mengatakan bahwa mulai berhubungan seksual setelah 1 bulan pasca melahirkan. Hal ini juga didukung oleh hasil penelitian dalam sebuah studi. Hasil wawancara terhadap 10 subyek mengatakan 3 subyek mulai berhubungan seksual kira-kira 3 bulan setelah melahirkan. Sementara itu, 7 diantaranya mengatakan belum memikirkan tentang kapan akan mulai berhubungan seksual lagi (Suryati \& Elliya, 2011).

Berdasarkan hasil tabulasi silang antara rentang waktu melahirkan, usia dari pada ibu tersebut, status sosial ekonomi, pendidikan, pekerjaan, serta banyaknya pengalaman melahirkan dengan triangular love, pada dimensi passion dan intimacy masih terdapat subyek yang memiliki nilai rendah, sebaliknya untuk dimensi commitment pada semua subyek memiliki nilai yang tinggi. Nilai rendah pada dimensi seperti intimacy dan passion jika dilihat dari hasil tabulasi silang hanya berjumlah dibawah 10 orang dari 392 subyek, jadi belum benar-benar dapat dipastikan.

Tingginya nilai commitment pada setiap subyek dapat disebabkan karena commitment merupakan sesuatu hal yang tidak berwujud. Jika dilihat sesuai teori, commitment adalah elemen kognitif, merupakan keputusan untuk mencintai dan tetap bersama orang yang dicintainya 
(Papalia, et al, 2009). Dibandingkan dengan intimacy dan passion, commitment lebih sulit dirasakan wujudnya, sehingga membuat orang binggung untuk merasakan commitment dibandingkan dengan intimacy dan passion yang lebih terlihat wujudnya.

\section{KESIMPULAN DAN SARAN}

Berdasarkan pengolahan data yang telah dilakukan untuk mengetahui gambaran triangular love of Sternberg pada ibu setelah pasca melahirkan dan pasangannya, diperoleh hasil bahwa baik suami maupun istri memiliki triangular love yang cenderung tinggi setelah pasca melahirkan. Hanya saja, dimensi passion merupakan dimensi yang paling rendah dibandingkan kedua dimensi lainnya setelah pasca melahirkan pada istri maupun pada suami. Meskipun passion merupakan dimensi yang paling rendah dibandingkan dengan intimacy dan commitment, namun masih dalam kategori tinggi karena nilainya di atas 2,5.

Saran untuk penelitian selanjutnya adalah lebih banyak dalam pengambilan jumlah sampel sehingga data yang didapatkan juga lebih baik hasilnya. Selain jumlah sampel yang lebih banyak, disarankan juga jumlah dari setiap sampel diusahakan seragam, sehingga hasil yang didapatkan lebih akurat lagi. Kemudian area pengambilan subyek juga diperluas tidak hanya di Jakarta saja, namun dapat mencakup wilayah Jabodetabek atau wilayah lain yang cakupannya lebih luas. Selain itu bagi penelitian selanjutnya dapat mengkaitkan dengan beberapa variabel berbeda tidak hanya dari variabel triangular of love saja, hal tersebut dapat memberikan sumbangan pengetahuan bagi ilmu psikologi yang lebih baik lagi.

Saran dapat diberikan khususnya untuk pasangan suami istri setelah pasca melahirkan, ketika memiliki anak suami dan istri harus memiliki persiapan untuk beradaptasi dengan perubahan setelah pasca melahirkan. Adaptasi dapat dilakukan dengan membuat membaca buku-buku pegetahuan terkait dengan pasca melahirkan. Adaptasi juga dapat dilakukan dengan bertanya kepada orang yang telah memiliki pengalaman pasca melahirkan. Dengan adanya adaptasi yang dimiliki oleh pasangan suami istri, diharapkan jika terjadi masalah akibat perubahan tersebut setidaknya dampak dari masalah tersebut dapat diminimalkan sehingga hubungan suami dan istri tetap harmonis.

Keseimbangan ketiga unsur triangular of love sangat penting untuk menciptakan hubungan yang baik dan tahan lama, namun jika dilihat dari hasil yang diperoleh dimensi passion cenderung paling rendah jika dibandingkan dengan dimensi commitment dan intimacy. Saran yang dapat diberikan dari hasil tersebut adalah hendaknya pasangan suami istri mencari cara untuk mensiasati rendahnya dimensi passion tersebut, misalkan dengan meningkatkan komunikasi antara pasangan, sehingga diharapkan tidak timbul masalah akibat passion yang cenderung lebih rendah dari intimacy dan commitment setelah pasca melahirkan.

Pasangan suami istri hendaknya sering menghabiskan waktu berdua, misalkan meluangkan akhir pekan untuk keluar makan malam. Hal tersebut dapat meningkatkan intimacy dalam hubungan suami istri untuk mengimbangi passion yang rendah setelah tahap pasca melahirkan. Dukungan keluarga diperlukan. Keluarga sebaiknya dapat membantu untuk merawat anak.

Bagi suami, hendaknya siap untuk berbagi tugas dengan istri dalam mengurus, sehingga istri tidak merasa ditinggalkan sendirian. Suami sebaiknya memahami kondisi emosi istri yang mungkin mengalami simtom depresi postpartum dengan gangguan baby blues. Istri juga 
hendaknya lebih memperhatikan penampilan dan merawat diri setelah melahirkan. Cara yang dapat dilakukan antara lain dengan menjaga pola makan, olahraga, serta berpenampilan baik. Hal ini bertujuan agar istri dapat berperan sebagai istri dan ibu yang baik.

\section{Ucapan Terima Kasih}

Dengan selesainya penelitian ini saya ingin berterima kasih kepada seluruh partisipan dan orangorang yang terlibat dalam penelitian ini yang tidak dapat saya sebutkan satu persatu.

\section{REFERENSI}

Amanto, P. R., Johnson, D. R., Booth, A., \& Rogers, S. J. (2003). Continuity and change in marital quality between 1980 and 2000. Journal of Marriage and Family (65), 1-22.

Badan Kependudukan dan Keluarga Berencana Nasional. (2014). Jarak kehamilan dan pola asuh yang baik. Diunduh dari www.bkkbn.go.id.

Bobak \& Irene, M. (2005). Buku ajar keperawatan maternitas, Edisi 4. Alih Bahasa : Maria A, W. Jakarta: EGC.

Carandang, M. N. S., Guda, I. V. P. (2015). Indicators of marital satisfaction of batangueno couples: Components of love and the other external factors in marriage. E-Journal of International Journal of Information and Education Technology, 5. Retrieved from http://www.ijiet.org/papers/477-N20003.pdf

Compton, W. C. (2005). Introduction to positive psychology. California: Thompson Wadsworth. Danuatmaja, B. (2003). 40 hari pasca persalinan, masalah dan solusinya. Jakarta: Puspa Swara.

Ibrahim, F., Rahma., Ikhsan, M. (2012). Faktor-faktor yang berhubungan dengan depresi postpartum di RSIA Pertiwi Makassar tahun 2012. Retrieved from http://repository.unhas.ac.id/bitstream/handle/123456789/4250/Fatma\%20Ibrahim\%20\% 28K11108297\%29.pdf? sequence=1

Lawrence, E., Cobb, R. J., Rothman, A. D., Rothman, M. T., Bradbury, T. N. (2008). Marital satisfaction across the trantition to parenthood. E-Journal of Journal Farm Psychol, 22(1), 41-50. Diunduh dari http://www.ncbi.nlm.nih.gov/pmc/articles/PMC2367106/

Murtiningsih, A. (2012). Mengenal baby blues dan pencegahannya. Jakarta: Dunia Sehat.

Olson, D.H., \& Defrain, J. (2006). Marriage and the family $\left(5^{\text {th }}\right)$. California: Mayfield.

Papalia, D. E., Olds, S. W., Feldman, R. D. (2009). Human development $\left(11^{\text {th }}\right)$. NY:

McGraw Hill.

Petersen, A. (2011). So cute, so hard on a marriage. Diunduh dari www.wjs.com

Prawirohardjo, S. (2008). Ilmu kandungan. Jakarta: Yayasan Prawirohardjo Bina Pustaka Sarwono.

Retnaningtyas, D. F. (2007). Komponen cinta pada individu yang telah menikah menurut Triangular Theory of Love. Diunduh dari http://www.library.usd.ac.id/Data\%20PDF/F.\%20Psikologi/Psikologi/029114031.pdf

Rice, F. P. (1999). Intimate relationships, marriage, \& families. Callifornia : Mayfield.

Sternberg, R. J. (1997). Construction validation of a triangular love scale. European Journal of Social Psychology, 313-335. Retrieved from https://teachersh.scis-his.net/tmrak/wpcontent/uploads/sites/60/2013/11/Sternberg-97-Triangular-Theory-of-Love.pdf

Sternberg, R. J. (1998). Cupid's arrow : the course of love through time. NY: Cambridge University.

Sternberg, R. J. (1987). The triangular of love. NY: Basic Books, Inc. 
Strong. B., DeVault, C., Cohen, T. F. (2011). The marriage and family experience (11 $\left.{ }^{\text {th }}\right)$. Canada: Wadsworth.

Suryati, Y., Elliya, O. (2013). Hubungan pengetahuan suami dengan minat berhubungan intim ibu postpartum di Rumah Sakit Dustira Cimahi. Jurnal Kesehatan Kartika, 18-27. Diunduh dari http://www.stikesayani.ac.id/publikasi/e-journal/files/2011/201112/201112003.pdf

Weiten, W., \& Liyod, M. A. (2006). Psychology applied to modern life ( $\left.8^{\text {th }}\right)$. California: Thompson Wadsworth.

Yel (Agustus, 2013). 1 dari 5 suami paksa istrinya segera langsing setelah melahirkan. Diunduh dari http://www.vemale.com. 